\title{
Efficacy of ultraviolet radiation and hydrogen peroxide oxidation to eliminate large number of pharmaceutical compounds in mixed solution
}

\author{
*R. R. Giri; H. Ozaki; Y. Takayanagi; S. Taniguchi; R. Takanami
}

Osaka Sangyo University, 3-1-1 Nakagaito, Daito City, 574-8530 Osaka, Japan

Received 15 July 2010; $\quad$ revised 4 October 2010; accepted 23 November 2010; $\quad$ available online 1 December 2010

\begin{abstract}
Ultraviolet photolysis and ultraviolet and hydrogen peroxide oxidation of fourteen commonly used pharmaceutical compounds and two personal care products in mixed solution using low pressure ultraviolet lamp was investigated in laboratory batch experiments. Removal of the compounds followed the first-order reaction kinetic. Three distinct impacts of hydrogen peroxide on ultraviolet and hydrogen peroxide oxidation of the compounds (positive, negative and no significant effect) were observed. Removal behavior of the several tested compounds in mixed solution varied significantly than their respective behavior in absence of coexisting compounds. Clofibric acid, diclofenac, fenoprofen, isopropylantipyrine, ketoprofen, phenytoin and triclosan were removed very efficiently ( $>96 \%$ ) by ultraviolet photolysis alone. Residual hydrogen peroxide during ultraviolet and hydrogen peroxide oxidation was quantitated for the first time. Hydrogen peroxide addition to ultraviolet photolysis was not worthy for majority of the tested compounds as their removal did not increase significantly and very big fractions (> $85 \%$ ) of the added hydrogen peroxide $(0.29 \sim 1.47 \mathrm{mM})$ remained unused presumably due to small fluence of the lamp, very small molar absorption for hydrogen peroxide at $254 \mathrm{~nm}(27.06 / \mathrm{M} . \mathrm{cm})$ and acidic $\mathrm{pH}$ of reaction solution $(<5.7)$. Further exploration on ultraviolet and hydrogen peroxide oxidation with higher fluence lamp and alkaline solution $\mathrm{pH}$ will clarify usefulness of the method to treat pharmaceutical contaminated waters.
\end{abstract}

Keywords: Hydroxyl radical; molar absorption; removal rate; residual hydrogen peroxide; ultraviolet photolysis

\section{INTRODUCTION}

Ever increasing use of pharmaceutical compounds combined with inefficiency of conventional wastewater treatment methods to remove the compounds has resulted to their widespread detection in water environment. Oxidation of organic compounds in water using ultraviolet radiation and hydrogen peroxide $\left(\mathrm{UV} / \mathrm{H}_{2} \mathrm{O}_{2}\right)$ is widely investigated (Perkowski and Ledakowicz, 2002; Rauf et al., 2005; Shu and Chang, 2006; Abdullah et al., 2007; Alshamsi et al., 2007; Samarghandi et al., 2007), and the method is generally considered as a promising one (Lopez et al., 2003; Vonga et al., 2004; Pereira et al., 2007a). Several literatures demonstrated degradations of commercial dyes by $\mathrm{UV} / \mathrm{H}_{2} \mathrm{O}_{2}$ in aqueous solutions. Carmine degradation was enhanced at high $\mathrm{pH}$ in alkaline region, and presence of bromide, chloride, acetate, sulfate, silver and bicarbonate ions were found to have negative impact

$\bar{\triangle}$ *Corresponding Author Email: rabindra@cnt.osaka-sandai.ac.jp Tel.: +8172 8753001 on safranin-O degradation by $\mathrm{UV} / \mathrm{H}_{2} \mathrm{O}_{2}$ (Abdullah et al., 2007). Enhanced efficiency of $\mathrm{UV} / \mathrm{H}_{2} \mathrm{O}_{2}$ oxidation at alkaline $\mathrm{pH}$ region is attributed to hydroxyl radical formation (Qiao et al., 2005; Giri et al., 2010). Also, it is argued that decolorization of C. I. Acid Black 1 decreased with increasing solution $\mathrm{pH}$ due to decomposition of $\mathrm{H}_{2} \mathrm{O}_{2}$ into water and oxygen rather than hydroxyl radical formation (Shu and Chang, 2006; Igwe et al., 2008; Shah et al., 2009). A suitable $\mathrm{H}_{2} \mathrm{O}_{2}$ dosage showed enhanced performance of the process to degrade crystal violet (Alshami et al., 2007). Vogna et al., (2004) found $\mathrm{UV} / \mathrm{H}_{2} \mathrm{O}_{2}$ to be an efficient process compared to ozonation to degrade diclofenac. Pseudo first-order degradation rates of some pharmaceutical compounds with $\mathrm{UV} / \mathrm{H}_{2} \mathrm{O}_{2}$ increased significantly than those with UV photolysis alone (Kim et al., 2008). Low pressure (LP) UV lamps with $254 \mathrm{~nm}$ wavelength emission were used in almost all the earlier investigations, while a couple of them (Pereira et al., 2007b ; Canonica et 
al., 2008) argued that medium pressure (MP) lamps were more useful than LP lamps to effectively remove pharmaceutical compounds in water. Oxidation behaviors of an organic compound by UV and UV/ $\mathrm{H}_{2} \mathrm{O}_{2}$ may not be the same as its oxidation behaviors in mixed solutions with several coexisting compounds due to wide variation in their physicochemical characteristics and some limiting conditions (available photon energy, other oxidizing species such as hydroxyl radical etc.). Large numbers of pharmaceutical compounds have been detected in sewage influents/effluents (Kasprzyk-Hordern et al., 2009), and understanding their removal behaviors in mixed solutions can be very useful to estimate their fates in treatment facilities. But only few investigations (Kim et al., 2008) on their degradation behaviors in mixed solutions have been published till to date. Degradation of organic compounds by UV and UV-based oxidation methods depends largely on UV absorption by the compounds. Therefore, matching between available UV wavelengths and wavelengths absorbed by the compounds is a fundamental technique to understanding their oxidation behaviors. Moreover, fate of $\mathrm{H}_{2} \mathrm{O}_{2}$ during oxidation of organic contaminants by $\mathrm{UV} / \mathrm{H}_{2} \mathrm{O}_{2}$ can be a useful information to get better insight of their oxidation behaviors (Fagbote and Olanipekun, 2010; Aina et al., 2009). However, almost no earlier investigations on $\mathrm{UV} / \mathrm{H}_{2} \mathrm{O}_{2}$ process paid attention to fate of $\mathrm{H}_{2} \mathrm{O}_{2}$ in the system. Though Pereira et al., (2007a and b) mentioned about residual $\mathrm{H}_{2} \mathrm{O}_{2}$ measurement, no data is provided in the articles. This investigation aimed to elucidate removal characteristics of fourteen commonly used pharmaceuticals and two personal care products in mixed solutions in ultrapure water by $\mathrm{UV} / \mathrm{H}_{2} \mathrm{O}_{2}$ method using a low pressure lamp in laboratory batch experiments. The investigated compounds and some of their physicochemical properties are illustrated in Table 1. TCC and TCS in the table belong to personal care products. No information on chemical interaction among the selected compounds is available till to date. Therefore, it is presumed that no chemical interaction among them takes place in their mixed solutions. As this is a fundamental investigation on usefulness of $\mathrm{UV} / \mathrm{H}_{2} \mathrm{O}_{2}$ oxidation for removal of the compounds in mixed solution, no solution $\mathrm{pH}$ was adjusted in any of the experiments.
Several $\mathrm{H}_{2} \mathrm{O}_{2}$ doses were tested with the emphasis on removal of the compounds and fate of the added $\mathrm{H}_{2} \mathrm{O}_{2}$ during oxidation. This investigation was carried out in the laboratory of New Industrial $\mathrm{R}$ and D Center of Osaka Sangyo University, Japan between July 2009 and March 2010.

\section{MATERIALSAND METHODS}

\section{Materials}

IBP and TCC standards were purchased from Sigma-Aldrich Inc. and Tokyo Chemical Industry Co. Ltd., respectively. FEP, GFZ and CA standards were purchased from ICN Biomedicals Inc., LKT Lab Inc. and MP Biomedicals Inc., respectively. Standards of remaining compounds, aqueous $\mathrm{H}_{2} \mathrm{O}_{2}$ (30 \% by weight) and $\mathrm{Na}_{2} \mathrm{SO}_{3}$ (for quenching residual $\mathrm{H}_{2} \mathrm{O}_{2}$ in samples) were purchased from Wako Pure Chemicals Ltd. Nanocolor Peroxide 2 test kit (Merck, Germany) was used to measure residual $\mathrm{H}_{2} \mathrm{O}_{2}$ in samples. A low power $(10 \mathrm{~W})$ low pressure tubular mercury lamp (UVL10D, 254 nm, Sen Light Corporation, Japan) emitting mainly $254 \mathrm{~nm}$ wavelength was the source of UV irradiation. Reactor design and details of the experimental setup are given elsewhere (Giri et al., 2007). A recirculation cooler (CCA-111, Tokyo Rikakikai Co., Ltd.) was used for temperature control of reaction solution. A schematic diagram of the experimental setup is illustrated in Fig. 1.

\section{Experimental}

Stock solution of each compound $(1.0 \mathrm{~g} / \mathrm{L})$ was prepared in ultrapure water and stored at $4{ }^{\circ} \mathrm{C}$ for future use. Mixed aqueous solutions $(1.2 \mathrm{~L})$ of the sixteen compounds (100 $\mu \mathrm{g} / \mathrm{L}$ of each compound, i.e. $13.37 \times 10^{-2} \mu \mathrm{M} \sim 55.7910^{-2} \mu \mathrm{M}$ ) were prepared in ultrapure water using the stock solutions. Six initial $\mathrm{H}_{2} \mathrm{O}_{2}$ doses $(0 \sim 1.47 \mathrm{mM})$ were selected in this investigation based on a series of preliminary test experiments. The reaction solution was continuously mixed $(\approx 300 \mathrm{rpm}$ ) using a magnetic bar and stirrer under controlled temperature (25 \pm 2 ${ }^{\circ} \mathrm{C}$ ) in all the experiments. Solution $\mathrm{pH}$ was continuously monitored while the initial $\mathrm{pH}$ values in any of the experiments were not adjusted. Experiments were run for 30 min reaction time, samples were drawn at specified intervals for analysis. Residual $\mathrm{H}_{2} \mathrm{O}_{2}$ in samples were quenched using $\mathrm{Na}_{2} \mathrm{SO}_{3}$ solution $(1.0 \mathrm{~g} / \mathrm{L})$. UV absorption 
Int. J. Environ. Sci. Tech., 8 (1), 19-30, Winter 2011

Table 1: Physicochemical characteristics of the investigated compounds

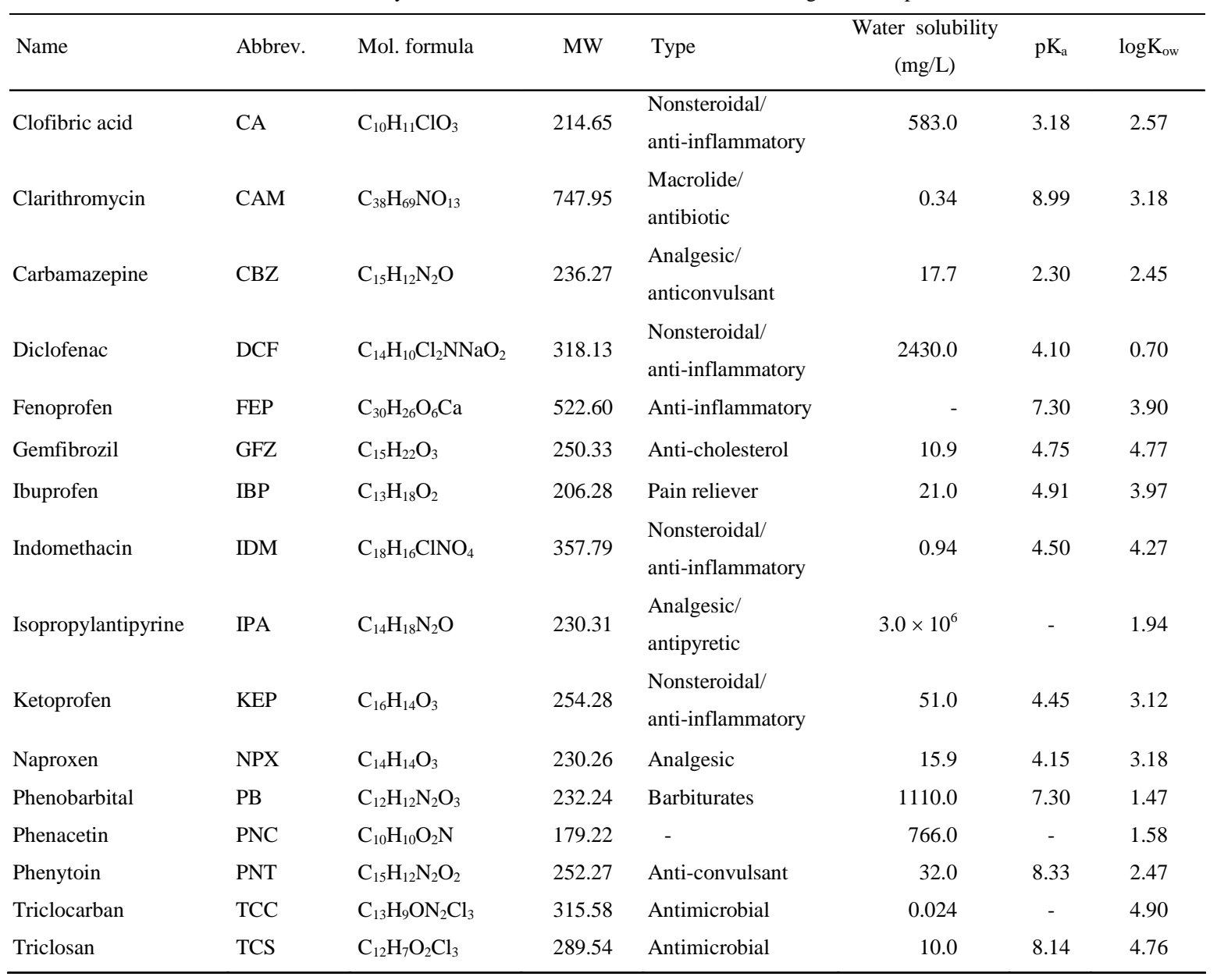

spectrum (200 $800 \mathrm{~nm}$ ) for each compound (1.0 mg/ $\mathrm{L})$ and $\mathrm{H}_{2} \mathrm{O}_{2}(9.79 \mathrm{mM})$ in ultrapure water were measured using U-3010 Spectrophotometer (Hitachi, Japan), and the corresponding molar absorption coefficient $(\varepsilon)$ value at $254 \mathrm{~nm}$ were calculated based on Beer-Lambert equation:

$\varepsilon=\frac{A}{c L}$

where, A: absorbance, c: concentration and L: path length.

\section{Analyses}

Remaining pharmaceuticals and personal care products in samples were analyzed using liquid chromatography tandem mass spectrometry (LCMS/
MS, Applied Biosystems). A turbo ion spray interface was used as the ion source, and mass detection was carried out using multiple reactions monitoring (MRM) mode. Eleven compounds (CA, DCF, FEP, GFZ, IBP, IDM, NPX, PB, PNT, TCC and TCS) were scanned in negative ion mode while the remaining (CAM, CBZ, KEP, IPA and PNC) were scanned in positive ion mode. Nitrogen was used as collision and curtain gas. Air was used as nebulizer and dryer gas. Ion source voltages in negative and positive scan modes were 4500.0 and 5000.0 respectively, while dryer gas temperatures for the two cases were 400 and $500{ }^{\circ} \mathrm{C}$, respectively. The LC system consisted of a binary pump, an auto sampler and a degasser unit (Agilent 1100 series). Chromatographic separation was performed using ZORBAX Eclipse XDB-C18 column 




Fig. 1: A schematic diagram showing reactor setup

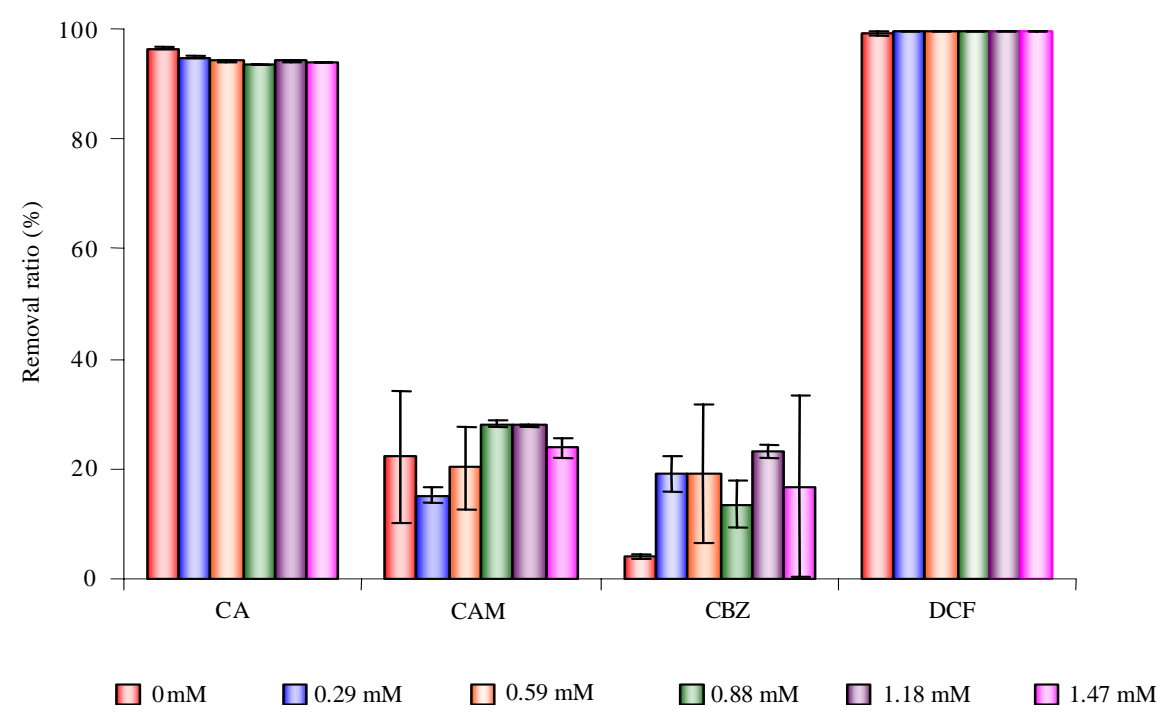

Fig. 2: $\mathrm{UV} / \mathrm{H}_{2} \mathrm{O}_{2}$ oxidation efficiencies for CA, CAM, CBZ and DCF (30 min reaction). The legend shows $\mathrm{H}_{2} \mathrm{O}_{2}$ concentrations 




Fig. 3: UV/ $\mathrm{H}_{2} \mathrm{O}_{2}$ oxidation efficiencies for FEP, GFZ, IBP and IDM (30 min reaction). The legend shows $\mathrm{H}_{2} \mathrm{O}_{2}$ concentrations

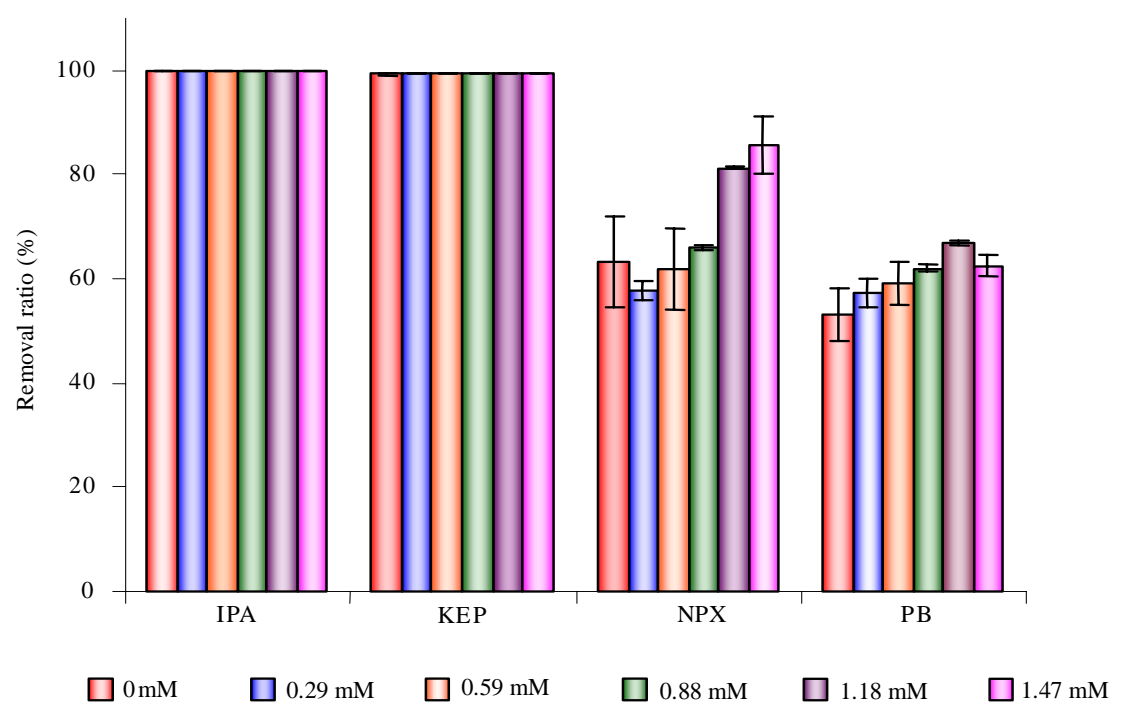

Fig. 4: $\mathrm{UV} / \mathrm{H}_{2} \mathrm{O}_{2}$ oxidation efficiencies for IPA, KEP, NPX and PB (30 min reaction). The legend shows $\mathrm{H}_{2} \mathrm{O}_{2}$ concentrations

$(2.1 \times 150 \mathrm{~mm}, 3.5 \mu \mathrm{m})$ with $200 \mu \mathrm{L} / \mathrm{min}$ mobile phase flow rate, $10 \mu \mathrm{L}$ sample injection volume and column temperature fixed at $40{ }^{\circ} \mathrm{C}$. Mobile phases for negative scan mode were: $0.1 \%(\mathrm{v} / \mathrm{v})$ acetic acid in $2.0 \mathrm{mM}$ ammonium acetate in ultrapure water (A) and acetonitrile (B), while $0.1 \%(\mathrm{v} / \mathrm{v})$ formic acid in ultrapure water and acetonitrile respectively were $\mathrm{A}$ and B in case of positive scan mode. Flow rate for A was set to $90 \%$ from 0 to $2 \mathrm{~min}$, which linearly decreased to $0 \%$ at $7 \mathrm{~min}$ and the same continued until $15 \mathrm{~min}$. Then the value increased again to $90 \%$ at $15.1 \mathrm{~min}$ and continued the same until the end (i.e. $20 \mathrm{~min}$ ). Residual hydrogen peroxide in samples was determined by photometric method using Nanocolor 


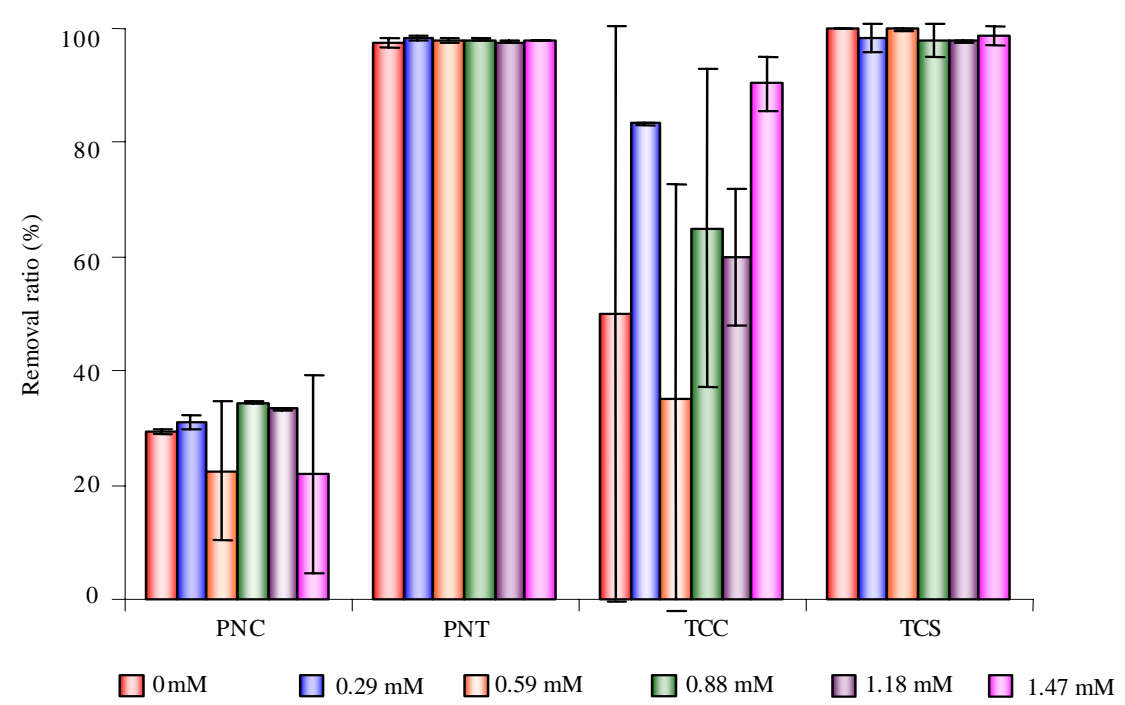

Fig. 5: UV/ $\mathrm{H}_{2} \mathrm{O}_{2}$ oxidation efficiencies for PNC, PNT, TCC and TCS (30 min reaction). The legend shows $\mathrm{H}_{2} \mathrm{O}_{2}$ concentrations

peroxide tube test kits and Odyssey DR/2500 spectrophotometer (HACH) at $620 \mathrm{~nm} \mathrm{UV}$ wavelength. UV emission intensity of UV lamp was measured using UV Spectroradiometer (USR-30, Kansai Scientific Instruments Co. Ltd., Japan).

\section{RESULTS AND DISCUSSION}

All the results presented in this section are average values of at least three similar batch experiments, and the error bars in figures indicate standard variation of the results.

\section{Removal of compounds}

Preliminary degradation tests for the selected compounds by $\mathrm{UV} / \mathrm{H}_{2} \mathrm{O}_{2}$ using a wide range of initial $\mathrm{H}_{2} \mathrm{O}_{2}$ doses were carried out first. Then six different $\mathrm{H}_{2} \mathrm{O}_{2}$ doses based on the observed removal performances in the preliminary tests were chosen for further tests. Average removal efficiencies for the compounds at the end of 30-min reaction time are illustrated in Fig. 2 through Fig. 5. The sixteen compounds can be divided into three distinct groups based on their removal efficiencies. The removals for CA, DCF, FEP, IPA, KEP, PNT and TCS were over 95 $\%$ irrespective of $\mathrm{H}_{2} \mathrm{O}_{2}$ doses. Negative impact of increasing $\mathrm{H}_{2} \mathrm{O}_{2}$ dosage was observed in case of CA and FEP removals. CAM, CBZ and PNC were very difficult to degrade by both $\mathrm{UV}$ and $\mathrm{UV} / \mathrm{H}_{2} \mathrm{O}_{2}(<30$ $\%$ removal efficiencies) within the range of tested $\mathrm{H}_{2} \mathrm{O}_{2}$ doses. Moreover, no specific trends in their removals were observed with increasing $\mathrm{H}_{2} \mathrm{O}_{2}$ dose. Removals of GFZ, IBP, IDM, NPX and PB varied between $40 \%$ and $80 \%$. The removal efficiencies for these compounds, in general, increased with increasing $\mathrm{H}_{2} \mathrm{O}_{2}$ dose. No specific trend was observed in case of TCC removal. The initial TCC concentrations in mixed solutions were very low and not consistent in all the tests possibly due to very small water solubility of the compound, resulting to large errors in average removal efficiencies (Fig. 5).

UV photolysis of DCF in this investigation was very large ( $>95 \%$ ) compared to earlier reported values of $27 \%$ (Canonica et al., 2008) and $39 \%$ (Vonga et al., 2004) with similar experimental conditions. The extremely low UV photolysis of CBZ was consistent to earlier results (Vonga et al., 2004; Pereira et al., 2007a) while relatively small removals of the compound by $\mathrm{UV} / \mathrm{H}_{2} \mathrm{O}_{2}$ (Fig. 2) may be attributed to low UV fluence (Pereira et al., 2007a). Furthermore, the authors did not observe significant improvements in CA removals by $\mathrm{UV} / \mathrm{H}_{2} \mathrm{O}_{2}$. More interestingly, CA removals decreased with increasing $\mathrm{H}_{2} \mathrm{O}_{2}$ doses in this investigation. IBP and PNT removals by UV photolysis in mixed solution in this 
Table 2: Apparent first-order removal rate $(\mathrm{k})$ values for the selected compounds (concentration of each compound: $13.4 \times 10^{-2}$ $\mu \mathrm{M} \sim 55.8 \times 10^{-2} \mu \mathrm{M}$ ) in mixed solution by $\mathrm{UV} / \mathrm{H}_{2} \mathrm{O}_{2}$ oxidation and corresponding molar absorption coefficient $(\varepsilon)$ values at $254 \mathrm{~nm}$

\begin{tabular}{|c|c|c|c|c|c|c|c|}
\hline \multirow{2}{*}{ Compound } & \multicolumn{6}{|c|}{ k values (h) with initial $\mathrm{H}_{2} \mathrm{O}_{2}$ concentration (mM) } & \multirow{2}{*}{$\begin{array}{c}\varepsilon \\
(/ \mathrm{M} / \mathrm{cm})\end{array}$} \\
\hline & 0 & 0.29 & 0.59 & 0.88 & 1.18 & 1.47 & \\
\hline CA & 6.80 & 6.00 & 5.74 & 5.55 & 5.78 & 5.61 & -214.65 \\
\hline CAM & 0.46 & 0.74 & 0.74 & 0.87 & 0.66 & 0.61 & 4487.70 \\
\hline CBZ & 0.12 & 0.30 & 1.68 & 0.27 & 0.52 & 0.32 & 6143.02 \\
\hline DCF & 44.39 & 43.90 & 46.50 & 48.35 & 45.16 & 47.70 & 3499.43 \\
\hline FEP & 9.44 & 8.88 & 9.86 & 8.10 & 6.55 & 7.01 & 1045.20 \\
\hline GFZ & 0.31 & 0.88 & 1.88 & 2.15 & 3.04 & 3.20 & 0 \\
\hline IBP & 0.86 & 1.35 & 1.74 & 1.30 & 1.44 & 1.83 & 1237.68 \\
\hline IDM & 1.36 & 2.35 & 4.81 & 4.59 & 6.28 & 7.08 & 16100.50 \\
\hline IPA & 13.02 & 13.90 & 14.84 & 14.72 & 18.14 & 20.01 & 8291.16 \\
\hline KEP & 149.36 & 149.63 & 144.17 & 145.10 & 142.88 & 149.67 & 16017.7 \\
\hline NPX & 2.46 & 2.10 & 1.86 & 2.38 & 3.32 & 3.90 & 8519.62 \\
\hline PB & 1.53 & 1.85 & 2.00 & 1.64 & 2.28 & 2.04 & 1625.68 \\
\hline PNC & 0.70 & 0.74 & 0.62 & 0.85 & 0.80 & 0.62 & 1245.40 \\
\hline PNT & 7.46 & 8.27 & 7.84 & 7.94 & 7.66 & 7.83 & 1261.35 \\
\hline TCC & 5.23 & 4.32 & 1.16 & 2.56 & 2.59 & 5.83 & 1223.20 \\
\hline TCS & 20.16 & 16.00 & 18.08 & 18.10 & 11.12 & 11.14 & 2605.86 \\
\hline
\end{tabular}

investigation (38\% and $97 \%$ respectively) were quite larger than the values (28\% and $87 \%$ respectively) reported earlier (Yuan et al., 2009), where UV photolysis experiments were carried out with individual compounds (i.e. IBP and PNT separately). NPX and KEP removals by UV photolysis and UV/ $\mathrm{H}_{2} \mathrm{O}_{2}$ oxidation were more or less consistent to the removals reported earlier.

\section{Removal kinetic and behaviors}

Removals of the selected compounds by UV and $\mathrm{UV} / \mathrm{H}_{2} \mathrm{O}_{2}$ in mixed solutions were well-described $\left(\mathrm{R}^{2} \geq 0.98\right)$ by the first-order reaction kinetic. The apparent first-order removal rate $(k)$ values for the compounds are illustrated in Table 2 . The $\mathrm{k}$ values for the sixteen compounds greatly varied. The compounds can roughly be grouped into two distinct categories based on the k values. CA, DCF, FEP, IPA, KEP, PNT and TCS exhibited significantly larger $\mathrm{k}$ values (up to 20-folds) than those of CAM, CBZ, GFZ, IBP, IDM, NPX, PB and PNC.
The $\mathrm{k}$ values for majority of the investigated compounds (e.g. CAM, CBZ, GFZ, IBP, IDM, NPX, $\mathrm{PB}, \mathrm{PNC}, \mathrm{DCF}$ and IPA) increased with increasing $\mathrm{H}_{2} \mathrm{O}_{2}$ doses. But, the values (excluding for GFZ, IBP, IDM, NPX and IPA) attenuated at larger $\mathrm{H}_{2} \mathrm{O}_{2}$ doses, which was consistent to an earlier report (Pereira et al., 2007b). Kim et al., (2008) reported significantly increased $k$ values for FEP, NPX, CAM, KEP, DCF, IDM, CBZ and IPA with $\mathrm{UV} / \mathrm{H}_{2} \mathrm{O}_{2}(0.14 \mathrm{mM}$ initial $\mathrm{H}_{2} \mathrm{O}_{2}$ dose) compared to those with UV only. Moreover, decreased CBZ and NPX removal rates with larger $\mathrm{H}_{2} \mathrm{O}_{2}$ doses were also reported (Pereira et al., 2007b). But this tendency was observed in case of CA, FEP and TCS (Table 2) in this investigation. The decreased CA photodegradation and $k$ value in presence of $\mathrm{H}_{2} \mathrm{O}_{2}$ was contrary to a result reported earlier (Andreozzi et al., 2003). No significant improvements in $\mathrm{k}$ values were observed for KEP and PNT with increasing $\mathrm{H}_{2} \mathrm{O}_{2}$ doses possibly due to more than $98 \%$ removals of the compounds by UV photolysis alone (Fig. 4 and Fig. 5). But DCF and IPA exhibited different behaviors than those of KEP 
and PNT. The $\mathrm{k}$ values for DCF and IPA increased significantly with increasing $\mathrm{H}_{2} \mathrm{O}_{2}$ doses despite more than 99 \% removals of the compounds by UV photolysis alone (Fig. 2 and Fig. 4). Consistent to an earlier report (Lin and Reinhard, 2005), KEP was the most easily photodegraded compound. The $\mathrm{k}$ values for NPX, CAM, DCF and CBZ in this investigation were similar to those of Kim et al., (2008), but the values for KEP and IPA were very large. Yuan et al., (2009) investigated photodegradation of PNT and IBP separately using a low pressure UV lamp with similar experimental conditions to those of this investigation. Though UV photolysis rate for PNT in this investigation (7.46 /h) was very close to the value $(7.20 / \mathrm{h})$ reported in Yuan et al., (2009), value for IBP in the literature $(1.08 / \mathrm{h})$ was significantly larger than that observed in this investigation $(0.86 / \mathrm{h})$. Pereira et al., (2007a) also investigated degradation of six pharmaceutical compounds in mixed solution by UV photolysis and $\mathrm{UV} / \mathrm{H}_{2} \mathrm{O}_{2}$ using low pressure UV lamp with similar experimental conditions. But they used only one $\mathrm{H}_{2} \mathrm{O}_{2}$ dose $(0.29 \mathrm{mM})$ with $\mathrm{UV} / \mathrm{H}_{2} \mathrm{O}_{2}$ process. The reported UV photolysis rate for CA (4.2/h) in Pereira et al., (2007a) was quite smaller than that observed in our experiments $(6.8 / \mathrm{h})$. Moreover, they found drastic increase in CA removal rate by $\mathrm{UV} / \mathrm{H}_{2} \mathrm{O}_{2}$ (71.4 $/ \mathrm{h}$ ), while decreasing tendency in $\mathrm{k}$ value was observed in our case (Table 2). The UV photolysis rate for NPX in our experiments was almost 2.5-folds larger than the value $(0.99 / \mathrm{h})$ reported in Pereira et al., (2007a). Similar to CA, k value for NPX with UV/ $\mathrm{H}_{2} \mathrm{O}_{2}(74.4 / \mathrm{h})$ was very large than that with UV photolysis in the literature, while the value for NPX decreased in our experiments (Table 2). UV photolysis rate for CBZ in our experiments was almost 1.5 -folds larger than the value $(0.08 / \mathrm{h})$ reported in Pereira et al., (2007a). The k value for $\mathrm{CBZ}$ with $\mathrm{UV} / \mathrm{H}_{2} \mathrm{O}_{2}(80.4 / \mathrm{h})$ was very large compared to its UV photolysis rate. But the $\mathrm{k}$ value for CBZ with $\mathrm{UV} / \mathrm{H}_{2} \mathrm{O}_{2}$ was only 2.5 -folds of the UV photolysis rate value in our experiments. UV photolysis rate for KEP in our experiments was about 1.9-folds larger than the reported value (76.8/h) in Pereira et al., (2007a). The k value for the compound with $\mathrm{UV} / \mathrm{H}_{2} \mathrm{O}_{2}$ is not given (due to its very fast disappearance) in Pereira et al., (2007a), while no significant change in its $\mathrm{k}$ value with $\mathrm{UV} / \mathrm{H}_{2} \mathrm{O}_{2}$ was observed in our case. It is apparent from this discussion that degradation behaviors of an organic compound with $\mathrm{UV}$ and $\mathrm{UV} / \mathrm{H}_{2} \mathrm{O}_{2}$ in presence and absence of coexisting organic compounds significantly vary, and number of coexisting compounds and their physicochemical characteristics might play greater role on its degradation behaviors. Three distinct impacts of increasing $\mathrm{H}_{2} \mathrm{O}_{2}$ doses in $\mathrm{UV} / \mathrm{H}_{2} \mathrm{O}_{2}$ oxidation system on removal efficiency and $\mathrm{k}$ value of the sixteen compounds using low power (10 W) low pressure UV lamp were observed in this investigation: (a) positive impact, (b) negative impact and (c) no significant impact. The enhanced removals and larger $\mathrm{k}$ values in $\mathrm{UV} / \mathrm{H}_{2} \mathrm{O}_{2}$ system were attributed to formation of hydroxyl radical $(\cdot \mathrm{OH})$ and dominance of 'OH-mediated oxidation (Pereira et al., 2007b; Yuan et al., 2009). The attenuation in removal efficiency and $\mathrm{k}$ value for some compounds with larger $\mathrm{H}_{2} \mathrm{O}_{2}$ doses was presumably due to scavenging action of excess $\mathrm{H}_{2} \mathrm{O}_{2}$ on UV energy and ' $\mathrm{OH}$ (Pereira et al., 2007a). $\mathrm{H}_{2} \mathrm{O}_{2}$ absorbs a fraction of available UV energy, which would otherwise be available for UV photolysis of target compounds in $\mathrm{UV} / \mathrm{H}_{2} \mathrm{O}_{2}$ system. UV photolysis of $\mathrm{H}_{2} \mathrm{O}_{2}$ produces ' $\mathrm{OH}$. However, if ${ }^{\circ} \mathrm{OH}$ is not produced by some reason and/or when $\mathrm{H}_{2} \mathrm{O}_{2}$ (in excess) scavenges generated ${ }^{\circ} \mathrm{OH}$, then the absorbed UV energy by $\mathrm{H}_{2} \mathrm{O}_{2}$ would not be useful to degrade target compounds resulting in smaller removal efficiencies.

\section{Molar absorption vs. photodegradation}

Molar absorption coefficient $(\varepsilon)$ value for each of the sixteen compounds was evaluated based on their measured UV absorption at $254 \mathrm{~nm}$, and the value was compared with corresponding apparent firstorder removal rate value (Table 2) obtained from UV photodegradation experiments carried out in mixed solution. The $\varepsilon$ values for CBZ and KEP obtained in this investigation were very close to the values (6070.0/M.cm and 15450.0 /M.cm respectively) given in Pereira et al., (2007a). But our values for CA and NPX were very different than those $(400.0 / \mathrm{M} . \mathrm{cm}$ and 4900.0 /M.cm respectively) given in the literature. The compounds with higher UV absorbance at $254 \mathrm{~nm}$ (i.e. $\varepsilon$ value) in general exhibited larger $k$ values (Table 2). But CA, CBZ, GFZ and IDM showed different behaviors. Despite negligibly small UV absorption by both CA (the negative value of $\varepsilon$ essentially implies no UV absorption) and GFZ, 


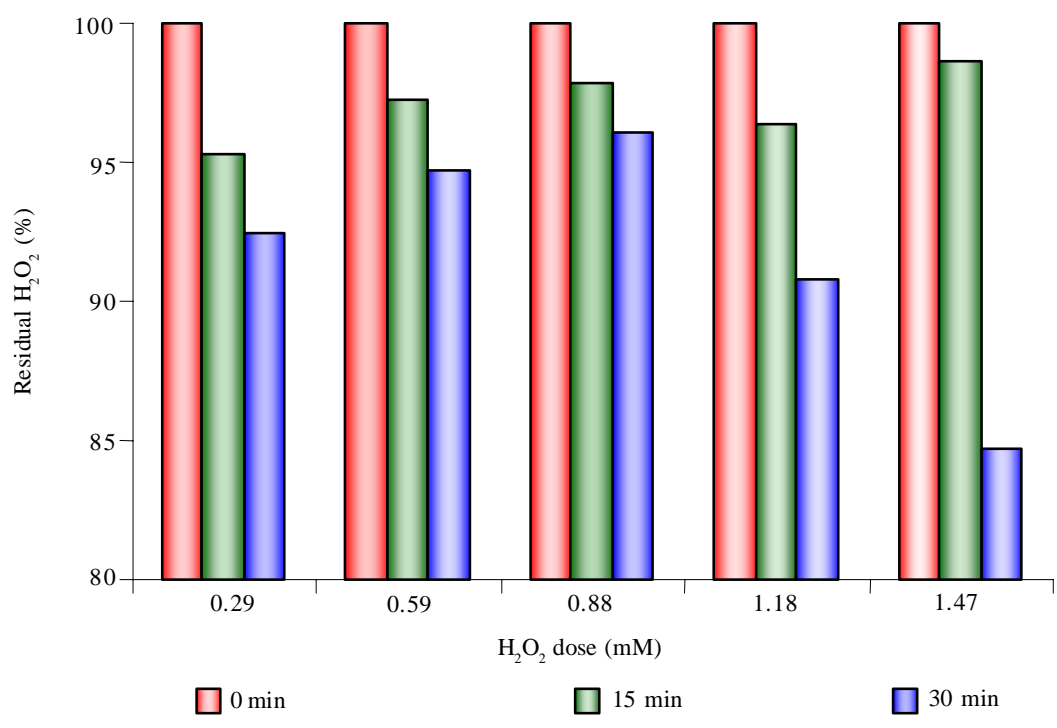

Fig. 6: Residual $\mathrm{H}_{2} \mathrm{O}_{2}$ concentration during $\mathrm{UV} / \mathrm{H}_{2} \mathrm{O}_{2}$ oxidation of pharmaceutical compounds in mixed solution

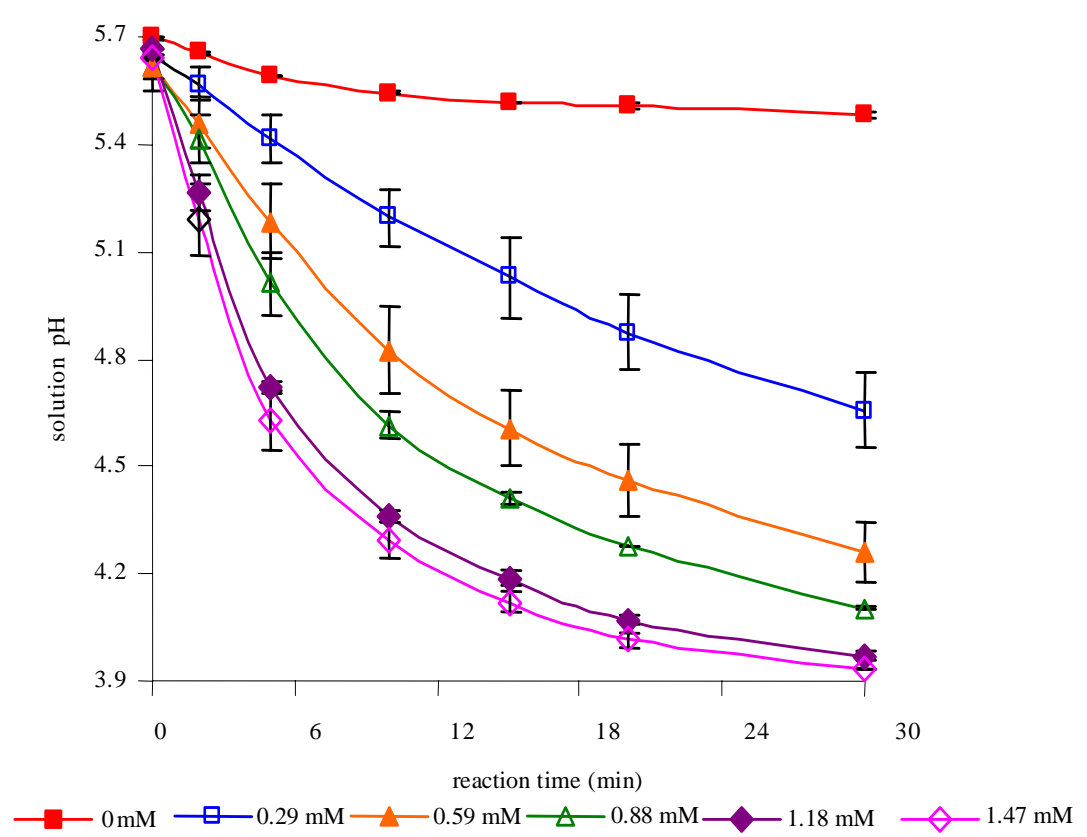

Fig. 7: Solution $\mathrm{pH}$ profiles during $\mathrm{UV} / \mathrm{H}_{2} \mathrm{O}_{2}$ oxidation of pharmaceutical compounds in mixed solution. The legend shows $\mathrm{H}_{2} \mathrm{O}_{2}$ concentrations

$\mathrm{k}$ value for CA was very large while the value for GFZ was significantly larger than that of CBZ. Despite almost the same $\varepsilon$ values for IDM and KEP, $\mathrm{k}$ value for the latter was more than one hundred folds of the former. Moreover, IBP, PNC, PNT and TCC exhibited very closer $\varepsilon$ values, but $k$ values for the latter two compounds were at least 6 -folds larger than those for IBP and PNC (Table 2). With similar k 
values for both IDM and PB, $\varepsilon$ value for the former was almost 10 -folds larger than that of the latter. UV absorbance (at $254 \mathrm{~nm}$ ) by $\mathrm{H}_{2} \mathrm{O}_{2}$ also was measured and the corresponding $\varepsilon$ value was evaluated. The value (27.06/M.cm) was very small compared to those of the investigated pharmaceutical compounds (excluding CA and GFZ). It is evident from the $\varepsilon$ and $\mathrm{k}$ values in Table 2 that molar absorption coefficient alone does not necessarily reflect photodegradation of a compound as one hundred percent of the absorbed photon energy may not be useful for degradation, which is known as "quantum yield". Furthermore, molar absorption coefficient and quantum yield values of an organic compound in presence and absence of several coexisting organic compounds can be expected to vary greatly due to variation in physicochemical characteristics of the compounds and limitation of available photon energy. The very small molar absorption coefficient value of $\mathrm{H}_{2} \mathrm{O}_{2}$ at $254 \mathrm{~nm}(27.06 / \mathrm{M} . \mathrm{cm})$ compared to those of the pharmaceutical compounds can be expected to decrease further in the mixed solution of sixteen compounds. Hydroxyl radical-mediated oxidation of organic compounds in $\mathrm{UV} / \mathrm{H}_{2} \mathrm{O}_{2}$ system leads to its enhanced efficiency, but UV photolysis of $\mathrm{H}_{2} \mathrm{O}_{2}$ is the first step for ${ }^{\circ} \mathrm{OH}$ generation. As molar absorption of $\mathrm{H}_{2} \mathrm{O}_{2}$ (27.06/M.cm) was very small and the value presumably further decreased in mixed solution, formation of $\mathrm{OH}$ may not be a major reaction pathway with $\mathrm{UV} / \mathrm{H}_{2} \mathrm{O}_{2}$ oxidation in this investigation. Moreover, $\mathrm{H}_{2} \mathrm{O}_{2}$ at large concentrations acts as ${ }^{\circ} \mathrm{OH}$ scavenger in $\mathrm{UV} / \mathrm{H}_{2} \mathrm{O}_{2}$ system (Pereira et al. 2007a). Therefore, 'OHmediated oxidation might not be a major reaction mechanism for the compounds in our experiments. With this discussion, one naturally gets curious on the fate of $\mathrm{H}_{2} \mathrm{O}_{2}$ in $\mathrm{UV} / \mathrm{H}_{2} \mathrm{O}_{2}$ system as no such information in our knowledge is available in published articles.

\section{Fate of $\mathrm{H}_{2} \mathrm{O}_{2}$}

Residual $\mathrm{H}_{2} \mathrm{O}_{2}$ concentrations at the beginning, middle and end of 30-min reaction time in $\mathrm{UV} / \mathrm{H}_{2} \mathrm{O}_{2}$ oxidation system with five different initial $\mathrm{H}_{2} \mathrm{O}_{2}$ doses are illustrated in Fig. 6. The added $\mathrm{H}_{2} \mathrm{O}_{2}$ concentrations gradually decreased with reaction time, but no specific trends in $\mathrm{H}_{2} \mathrm{O}_{2}$ concentration decrease were observed among the tested $\mathrm{H}_{2} \mathrm{O}_{2}$ doses. Remaining $\mathrm{H}_{2} \mathrm{O}_{2}$ at 15 min were 95.3, 97.3, 97.9, 96.4 and $98.6 \%$ respectively for $0.29,0.59,0.88,1.18$ and $1.47 \mathrm{mM}$ of initial $\mathrm{H}_{2} \mathrm{O}_{2}$ doses, while the values at $30 \mathrm{~min}$ were 92.5, 94.7, 96.1, 90.8 and $84.7 \%$, respectively. The residual $\mathrm{H}_{2} \mathrm{O}_{2}$ concentration at 30 min with $1.47 \mathrm{mM} \mathrm{H}_{2} \mathrm{O}_{2}$ dose decreased drastically compared to those of the remaining cases. Only few authors simply mentioned about residual $\mathrm{H}_{2} \mathrm{O}_{2}$ with $\mathrm{UV} / \mathrm{H}_{2} \mathrm{O}_{2}$ oxidation (Pereira et al., 2007a and b), but fate of $\mathrm{H}_{2} \mathrm{O}_{2}$ and its significance in the system are not discussed so far. It can clearly be observed (Fig. 6 ) that only small fractions of the initially added $\mathrm{H}_{2} \mathrm{O}_{2}$ were used in $\mathrm{UV} / \mathrm{H}_{2} \mathrm{O}_{2}$ oxidation during 30 min reaction period. For example, the highest $\mathrm{H}_{2} \mathrm{O}_{2}$ consumption in the system during the reaction period was with $1.47 \mathrm{mM} \mathrm{H}_{2} \mathrm{O}_{2}$ dose, and the value was only $15 \%$ of the added $\mathrm{H}_{2} \mathrm{O}_{2}$. In other words, more than $85 \%$ of the added $\mathrm{H}_{2} \mathrm{O}_{2}$ just remained in the system unused at the end of the reaction.

Pereira et al., (2007a and b) illustrated the impact of $\mathrm{UV}$ fluence on $\mathrm{UV} / \mathrm{H}_{2} \mathrm{O}_{2}$ oxidation of pharmaceutical compounds. Removal of pharmaceutical compounds in this investigation could possibly be enhanced further by using higher UV fluence values, but increasing UV fluence with the type of lamp we used (a standard LP/UV lamp) was not possible. The use of a fixed fluence UV lamp and the very large fractions of unused $\mathrm{H}_{2} \mathrm{O}_{2}$ (Fig. 6) indicated that available UV energy was possibly a limiting factor for $\mathrm{UV} / \mathrm{H}_{2} \mathrm{O}_{2}$ oxidation of the compounds in this investigation. What were more important with reference to $\mathrm{UV} / \mathrm{H}_{2} \mathrm{O}_{2}$ oxidation of the tested compounds that their removals were not in general significantly enhanced compared to their removals by UV photolysis and very large fractions of the added $\mathrm{H}_{2} \mathrm{O}_{2}$ remained unused by the end of 30 min reaction, which requires further treatment of the treated effluent before it is discharged to water bodies. An earlier investigation (Baumgarten et al., 2007) also concluded that adding $\mathrm{H}_{2} \mathrm{O}_{2}$ to UV photolysis of pharmaceutical compounds using LP lamp was unworthy though no information on residual $\mathrm{H}_{2} \mathrm{O}_{2}$ was given.

Pereira et al., (2007b) found medium pressure (MP) UV lamps to be more useful than LP lamps for efficient removal of pharmaceuticals by $\mathrm{UV} / \mathrm{H}_{2} \mathrm{O}_{2}$. The enhanced removal efficiency with MP lamps was the result of several wavelengths (200 $300 \mathrm{~nm}$ ) emitted 
by the lamps. But nothing is mentioned about fate of $\mathrm{H}_{2} \mathrm{O}_{2}$ in the system with MP lamps. It would therefore be worthy to explore on fate of $\mathrm{H}_{2} \mathrm{O}_{2}$ with $\mathrm{UV} / \mathrm{H}_{2} \mathrm{O}_{2}$ using MP lamps for more insight.

\section{Significance of solution $\mathrm{pH}$}

Solution $\mathrm{pH}$ is very important in photochemical reactions. Initial $\mathrm{pH}$ of reaction solutions in these experiments was not adjusted. Solution $\mathrm{pH}$ values during UV photolysis and $\mathrm{UV} / \mathrm{H}_{2} \mathrm{O}_{2}$ oxidation of the compounds in mixed solutions are illustrated in Fig. 7. Initial solution $\mathrm{pH}$ values before switching the UV lamp on were between 5.62 and 5.70. The values gradually decreased with reaction time. Moreover, the decrease in solution $\mathrm{pH}$ was more significant with increasing $\mathrm{H}_{2} \mathrm{O}_{2}$ dose (Fig. 7). Enhanced efficiency of $\mathrm{UV} / \mathrm{H}_{2} \mathrm{O}_{2}$ oxidation system is primarily attributed to ${ }^{\circ} \mathrm{OH}$-mediated reaction. But ${ }^{\circ} \mathrm{OH}$ generation due to $\mathrm{UV}$ photolysis of $\mathrm{H}_{2} \mathrm{O}_{2}$ is favorable only in alkaline $\mathrm{pH}$ region (Qiao et al., 2005). It is then apparent that the acidic solution $\mathrm{pH}$ values and their further decrease with time and larger $\mathrm{H}_{2} \mathrm{O}_{2}$ doses in $\mathrm{UV} / \mathrm{H}_{2} \mathrm{O}_{2}$ system might have negatively affected $\mathrm{OH}$ generation in this investigation. Therefore, adjusting solution $\mathrm{pH}$ to larger values (alkaline region) would be a possible way to enhance $\mathrm{H}_{2} \mathrm{O}_{2}$ photolysis with $\mathrm{UV} / \mathrm{H}_{2} \mathrm{O}_{2}$ oxidation.

\section{CONCLUSION}

$\mathrm{UV}$ photolysis and $\mathrm{UV} / \mathrm{H}_{2} \mathrm{O}_{2}$ oxidation of the sixteen compounds in mixed solution followed the first-order reaction kinetic. Oxidation behavior (i.e. removal efficiency and rate) of the several tested compounds in mixed solution varied significantly from their respective behavior in absence of coexisting organic compounds presumably due to wide variation in their physicochemical characteristics and limitation of available UV photon energy in the system. Three distinct effects of $\mathrm{H}_{2} \mathrm{O}_{2}$ on $\mathrm{UV} / \mathrm{H}_{2} \mathrm{O}_{2}$ oxidation of the compounds (positive, negative and no significant effect) were observed. CA, DCF, FEP, IPA, KEP, PNT and TCS were eliminated very efficiently (> $96 \%$ ) by UV photolysis alone, while $\mathrm{H}_{2} \mathrm{O}_{2}$ addition to UV was not very worthy to further enhancing removals of majority of the compounds. Residual $\mathrm{H}_{2} \mathrm{O}_{2}$ during $\mathrm{UV} / \mathrm{H}_{2} \mathrm{O}_{2}$ oxidation was quantitated for the first time. Very large fractions ( $>$ $85 \%)$ of the added $\mathrm{H}_{2} \mathrm{O}_{2}(0.29 \sim 1.47 \mathrm{mM})$ in $\mathrm{UV} / \mathrm{H}_{2} \mathrm{O}_{2}$ system remained unused presumably due to small UV fluence of the LP lamp, very small molar absorption coefficient value for $\mathrm{H}_{2} \mathrm{O}_{2}$ at $254 \mathrm{~nm}(27.06 / \mathrm{M} . \mathrm{cm})$ and acidic solution $\mathrm{pH}(<5.7)$. Further tests with $\mathrm{UV} / \mathrm{H}_{2} \mathrm{O}_{2}$ oxidation using higher UV fluence and alkaline solution pH are desirable to clarify usefulness of the method to treat pharmaceutical contaminated waters.

\section{ACKNOWLEDGEMENTS}

This research was carried out under "Collaboration with Local Communities” project financially supported by the Ministry of Education, Culture, Sports, Science and Technology (MEXT), Japan.

\section{RERERENCES}

Abdullah, F. H.; Fauf, M. A.; Ashraf, S. S., (2007). Photolytic oxidation of Safranin-O with $\mathrm{H}_{2} \mathrm{O}_{2}$. Dyes Pigm., 72 (3), 349-352 (4 pages).

Aina, M.; Matejka, G.; Mama, D.; Yao, B.; Moudachirou, M., (2009). Characterization of stabilized waste: Evaluation of pollution risk. Int. J. Environ. Sci. Tech., 6 (1), 59-165 (7 pages).

Alshamsi, F. A.; Albadwawi, A. S.; Alnuaimi, M. M.; Rauf, M. A.; Ashraf, S. S., (2007). Comparative efficiencies of the degradation of crystal violet using UV/hydrogen peroxide and fenton's reagent. Dyes Pigm., 74 (2), 283-287 (5 pages).

Andreozzi, R.; Capiro, V.; Marotta, R.; Radovnikovic, A., (2003). Ozonation and $\mathrm{H}_{2} \mathrm{O}_{2} / \mathrm{UV}$ treatment of clofibric acid in water: a kinetic investigation. J. Hazard. Mater., 103 (3), 233-246 (14 pages).

Baumgarten, S.; Schroder, H. F.; Charwath, C.; Lange, M.; Beier, S.; Pinnekamp, J., (2007). Evaluation of advanced treatment technologies for the elimination of pharmaceutical compounds. Water Sci. Tech., 56 (5), 1-8 (8 pages).

Canonica, S.; Meunier, L.; Gunten, U. V., (2008). Phototransformation of selected pharmaceuticals during UV treatment of drinking water. Water Res., 42 (1-2), 121-128 (8 pages).

Fagbote, E. O.; Olanipekun, E. O., (2010). Levels of polycyclic aromatic hydrocarbons and polychlorinated biphenyls in sediment of bitumen deposit impacted area. Int. J. Environ. Sci. Tech., 7 (3), 561-570 (10 pages).

Giri, R. R.; Ozaki, H.; Ishida, T.; Takanami, R.; Taniguchi, S., (2007). Synergy of ozonation and photocatalysis to mineralize low concentration 2,4-dichlorophenoxyacetic acid in aqueous solution. Chemosphere, 66 (9), 1610-1617 (8 pages).

Giri, R. R.; Ozaki, H.; Ota, S.; Takanami, R. Taniguchi, S., (2010). Degradation of common pharmaceuticals and personal care products in mixed solutions by advanced oxidation techniques. Int. J. Environ. Sci. Tech., 7 (2), 251260 (10 pages).

Igwe, J. C.; Abia, A. A.; Ibeh, C. A., (2008). Adsorption kinetics and intraparticulate diffusivities of $\mathrm{Hg}$, $\mathrm{As}$ and $\mathrm{Pb}$ ions on unmodified and thiolated coconut fiber. Int. J. Environ. Sci. Tech., 5 (1), 83-92 (10 pages).

Kasprzyk-Hordern, B.; Dinsdale, R. M.; Guwy, A. J., (2009). The removal of pharmaceuticals, personal care products, 
endocrine disruptors and illicit drugs during wastewater treatment and its impact on the quality of receiving waters. Water Res., 43 (2), 363-380 (18 pages).

Kim, I. H.; Tanaka, H.; Iwasaki, T.; Takubo, T.; Morioka, T.; Kato, Y., (2008). Classification of the degradability of 30 pharmaceuticals in water with ozone, UV and $\mathrm{H}_{2} \mathrm{O}_{2}$. Water Sci. Tech., 57 (2), 195-200 (6 pages).

Lin, A. Y.; Reinhard, M., (2005). Photodegradation of common environmental pharmaceuticals and estrogens in river water. Environ. Toxicol. Chem., 24 (6), 1303-1309 (7 pages).

Lopez, A.; Bozzi, A.; Mascolo, G.; Kiwi, J., (2003). Kinetic investigation on $\mathrm{UV}$ and $\mathrm{UV} / \mathrm{H}_{2} \mathrm{O}_{2}$ degradations of pharmaceutical intermediates in aqueous solution. J. Photochem. Photobiol. A., 156 (1-3), 121-126 (6 pages).

Pereira, V. J.; Linden, K. G.; Weinberg, H. S., (2007b). Evaluation of UV irradiation for photolytic and oxidative degradation of pharmaceutical compounds in water. Water Res., 41 (19), 4413-4423 (11 pages).

Pereira, V. J.; Weinberg, H. S.; Linden, K. G.; Singer, P. C., (2007a). UV degradation kinetics and modeling of pharmaceutical compounds in laboratory grade and surface water via direct and indirect photolysis at $254 \mathrm{~nm}$. Environ. Sci. Tech., 41 (5), 1682-1688 (7 pages).

Perkowski, J.; Ledakowicz, S., (2002). Decomposition of anthraquinone dye in the aqueous solution during advanced oxidation processes. Fibres and Textiles in Eastern Europe, October/December, 68-72 (5 pages).
Qiao, R. P.; Ma, Y. M.; Qi, X. H.; Li, N.; Jin, X. C.; Wang, Q. S.; Zhuang, Y. Y., (2005). Degradation of microcystin-RR by combination of $\mathrm{UV} / \mathrm{H}_{2} \mathrm{O}_{2}$ technique. Chin. Chem. Lett., 16 (9), 1271-1274 (4 pages)

Rauf, M. A.; Ashraf, S.; Alhadrami, S. N., (2005). Photolytic oxidation of Coomassie brilliant blue with $\mathrm{H}_{2} \mathrm{O}_{2}$. Dyes Pigm., 66 (3), 197-200 (4 pages).

Samarghandi, M. R.; Nouri, J.; Mesdaghinia, A. R.; Mahvi, A. H.; Nasseri, S.; Vaezi, F., (2007). Efficiency removal of phenol, lead and cadmium by means of $\mathrm{UV} / \mathrm{TiO}_{2} / \mathrm{H}_{2} \mathrm{O}_{2}$ processes. Int. J. Environ. Sci. Tech., 4 (1), 19-26 (8 pages).

Shah, B. A.; Shah, V. A.; Singh, R. R., (2009). Sorption isotherms and kinetics of chromium uptake from wastewater using natural sorbent material. Int. J. Environ. Sci. Tech., 6 (1), 77-90 (14 pages).

Shu, H. Y.; Chang, M. C., (2006). Development of a rate expression for predicting decolorization of C. I. Acid Black 1 in a UV/ $\mathrm{H}_{2} \mathrm{O}_{2}$ process. Dyes Pigm., 70 (1), 31-37 (6 pages).

Vonga, D.; Marotta, R.; Napolitano, A.; Andreozzi, R.; d'lschia, M., (2004). Advanced oxidation of the pharmaceutical drug diclofenac with $\mathrm{UV} / \mathrm{H}_{2} \mathrm{O}_{2}$ and ozone. Water Res., 38 (2), 414-422 (9 pages).

Yuan, F.; Hu, C.; Hu, X.; Qu, J.; Yang, M., (2009). Degradation of selected pharmaceuticals in aqueous solution with UV and $\mathrm{UV} / \mathrm{H}_{2} \mathrm{O}_{2}$. Water Res., 43 (6), 1766-1774 (9 pages).

\section{AUTHOR (S) BIOSKETCHES}

Giri, R. R., Ph.D. is a researcher in New Industrial R \& D Center of Osaka Sangyo University, 3-1-1 Nakagaito, Daito City, 574-8530 Osaka, Japan. Email: rabindra@cnt.osaka-sandai.ac.jp

Ozaki, H., D. is a professor in Department of Civil Engineering of Osaka Sangyo University, 3-1-1 Nakagaito, Daito City, 574-8530 Osaka, Japan. Email: ozaki@ce.osaka-sandai.ac.jp

Takayanagi, Y. is an undergraduate student in School of Engineering of Osaka Sangyo University, 3-1-1 Nakagaito, Daito City, 5748530 Osaka, Japan. Email: takayanagi@sub.osaka-sandai.ac.jp

Taniguchi, S., M. Eng. is a researcher in New Industrial R \& D Center of Osaka Sangyo University, 3-1-1 Nakagaito, Daito City, 574-8530 Osaka, Japan. Email: taniguch@cnt.osaka-sandai.ac.jp

Takanami, R., M. Eng. is a researcher in New Industrial R \& D Center of Osaka Sangyo University, 3-1-1 Nakagaito, Daito City, 5748530 Osaka, Japan. Email: r-nami@cnt.osaka-sandai.ac.jp

How to cite this article: (Harvard style)

Giri, R. R.; Ozaki, H.; Takayanagi, Y.; Taniguchi, S.; Takanami, R., (2011). Efficacy of ultraviolet radiation and hydrogen peroxide oxidation to eliminate large number of pharmaceutical compounds in mixed solution. Int. J. Environ. Sci. Tech., 8 (1), 19-30. 